Revista de Derecho

de la Pontificia Universidad Católica de Valparaíso

XXXV (Valparaíso, Chile, 2010, 2 Semestre)

[pp. $289-323$ ]

\title{
LOS BONOS SUBORDINADOS EN EL MARCO DEL SISTEMA FINANCIERO CHILENO
}

["Subordinated Bonds in the Chilean Financial System"]

Juan Luis Goldenberg Serrano*

\begin{abstract}
RESUMEN
Desde hace tiempo se ha pretendido que la estabilidad del sistema bancario se logre mediante una adecuada composición de los recursos propios de los bancos, extendiendo este concepto a instrumentos de deuda que se asemejen funcionalmente al capital. En el Derecho chileno, se ha pretendido esta asimilación únicamente por medio de la emisión de bonos subordinados, siguiendo el modelo originalmente propuesto por el Comité de Basilea de 1988. Pero desde aquellos tiempos se ha avanzado bastante en esta materia, por medio de una sucesión de directrices del mismo Comité y de la Unión Europea, que hasta el momento no han recibido acogida en nuestro país. El presente artículo tiene por objeto dar cuenta del concepto funcional de estos
\end{abstract}

\begin{abstract}
For a long time, the banking system reaching stability has been sought by means of the adequate combination of the banks ' own resources, expanding this concept to debt instruments that are functionally similar to capital. Chilean law has attempted this assimilation only by means of subordinate bond issuance, following the model originally proposed by the Basel Committee of 1988 . However, important progress regarding this matter has been made since then by means of a series of guidelines of the aforementioned Committee and the European Union that, so far, have not been accepted in our country. This article aims at accounting for the functional concept of these banks' own resources and for the different models to legally articulate the subordinated financ-
\end{abstract}

* Licenciado en Derecho por la Pontificia Universidad Católica de Chile y la Universidad de Salamanca, España; doctor en Derecho por la Universidad de Salamanca. Correo electrónico:jlgoldenberg@usal.es 
recursos propios de los bancos y de los diversos modelos para la articulación jurídica de las financiaciones subordinadas, para finalmente explicar de su régimen legal en Chile.

Palabras clave: Bancos, recursos propios, financiaciones subordinadas. ing. Finally, its legal regime in Chile will be explained.

KEYwORds: Banks, own resources, subordinate financing.

\section{INTRODUCCIÓN}

La inquietud respecto a la conservación de los niveles de seguridad y fortaleza patrimonial de las entidades de crédito se basa en la evidente importancia del sector financiero en la estabilidad económica de los países. De hecho, Rojo - con un acierto que se replica en la reciente crisis financiera-, agrega que "de ahí que tradicionalmente las empresas bancarias en dificultades escapen de la quiebra, bien por la acción del propio sector (a través de absorciones y de la adquisición de paquetes de control), bien por la intervención del poder público" . El descalabro del sistema financiero, probablemente producto de una debacle económica general, termina por sepultar las esperanzas de una solución a corto plazo, reemplazándola por una señal de angustia en los diversos mercados relacionados. Hoy por hoy, y dados los evidentes nexos entre los diferentes sectores económicos, el riesgo se acentúa precisamente en razón de su intercomunicación. La caída del sistema bancario pasa a ser consecuencia de la inestabilidad de otros sectores dada su función de colocación de recursos y el aumento del incumplimiento en la restitución de los fondos por parte de terceros; pero, a su vez, funcionará como causa de nuevas situaciones de crisis dada su función de captación e imposibilidad de hacer frente a sus obligaciones de restitución de los fondos recibidos.

En razón de lo anterior, los ordenamientos jurídicos han tenido especial cautela en establecer una regulación que asegure la seguridad y solidez del sistema bancario. Como señalaba de Vecchis: "Toda la legislación bancaria italiana -y, ciertamente no sólo la italiana- tiene como objetivo de fondo la estabilidad y eficiencia del sistema bancario; lo que, por cuanto se deduce, se traduce en adoptar como finalidad primaria de la acción de las autoridades de vigilancia bancaria la de asegurar un correcto y regular ejercicio de la relativa actividad, así como establecer condiciones para evitar la crisis”2

${ }^{1}$ Rojo Fernández-Río, Ángel, Crisis de la empresa y procedimientos concursales, en Anales de la Academia Matrisense del Notariado, 23 (1982), p. 271.

${ }^{2}$ DE Vecchis, Pietro, Aspectos jurídicos de las crisis bancarias en Italia, en VV.AA., Aspectos jurídicos de las crisis bancarias (Respuesta del ordenamiento jurídico) (Madrid, Gráficas Lorno, 1998), p. 85. 
Puede señalarse, sin temor a equívoco, que todo avance normativo en materia de seguridad del sistema bancario ha sido siempre reactivo a situaciones de inestabilidad económica ${ }^{3}$. En ellas, las reglas vigentes han probado ser insuficientes, de lo que deviene el interés en nuevas fórmulas que aseguren un control más eficaz.

Desde hace un buen tiempo, la preocupación se ha centrado dos aspectos: por un lado, en el establecimiento de reglas relativas a los requerimientos patrimoniales y, por otro, en las limitaciones a la actividad bancaria. En relación con el objeto del presente artículo, nos referiremos únicamente al primero de tales puntos. Las exigencias patrimoniales no sólo se refieren al imperativo de contar con un capital mínimo que sirva de sustento último a los intereses de los acreedores, sino también a la fijación de ciertas ratios financieras de liquidez y solvencia que aseguren el buen estado financiero de la entidad ${ }^{4}$.

En el establecimiento de las reglas que tratan sobre los requerimientos mínimos de capital de las entidades bancarias, como asimismo para efectos del cálculo de los niveles de liquidez y solvencia requeridos por su funcionamiento, tiene crucial importancia la determinación de qué debe entenderse por "recursos propios". Lo que siempre fue jurídicamente obvio parece no ser tan claro desde el punto de vista económico. Los ensayos de respuesta habían dado cuenta de la disparidad derivada de la estructura jurídico institucional del sistema crediticio con la posibilidad de recapitalización mediante el acceso al mercado de capitales de riesgo, especialmente, por su naturaleza, para la banca pública y las cajas de ahorro 5 .

A tales efectos, es evidente que los recursos propios de las entidades de crédito, al igual que para el resto de las sociedades, están constituidos primariamente por los aportes de capital. No obstante, la tendencia ha sido la incorporación de otros instrumentos - principalmente "híbridos financieros"- que, dadas sus características, cumplen similares funciones que el capital propiamente tal o capital primario ("core capital"), al menos, en cuanto a su capacidad de absorber pérdidas. De hecho, tal posibilidad es la primera

\footnotetext{
${ }^{3}$ Fernández Rodríguez, Tomás Ramón, Aspectos administrativos de las crisis bancarias, en VV. AA., Aspectos jurídicos de las crisis bancarias, cit. (n. 2), p. 199.

${ }^{4} \mathrm{~L}$ a necesidad de contar con regulaciones del capital bancario se han incrementado, entre otras razones, por la mayor exposición al riesgo por parte de las entidades financieras. Para una explicación de las razones de lo anterior, puede consultarse: TALMOR, Eli, A Normative Approach to Bank Capital Adequacy, en The Journal of Financial and Quantitative Analysis, 15 (1980) 4, pp. 787-788.

${ }^{5}$ Portale, Giuseppe (director), La recapitalizzazione delle aziende di credito (probleme e ipotesi), en Portale, Giuseppe (director), Ricapitalizzazione delle banche e nuovi strumenti di ricorso al mercato (Milano, Giuffré, 1983) p. 6.
} 
finalidad que se asigna a los recursos propios de las entidades de crédito 6 . Se pretende superar entonces la noción jurídica de "capital", fomentando el reconocimiento de su concepción más económica. Para ello, se ha atendido más a su función que a su ropaje.

La elección y clasificación de los recursos complementarios deben ajustarse a la finalidad pretendida mediante el establecimiento de las reglas de control de solidez y seguridad del sistema financiero. A este respecto, no debe olvidarse que la principal preocupación del Estado es la prevención de las consecuencias negativas de las crisis bancarias, y de ahí que no baste la asimilación económica del recurso complementario a los fondos propios, sino el establecimiento de un régimen jurídico del que ofrezca verdadera seguridad.

En este contexto surge el interés por las financiaciones subordinadas, entendiendo por tales la que resulta de la emisión de deuda (normalmente en forma de "bonos") que, en la escala de prelación de créditos, sólo se pagará una vez satisfechos todos los créditos valistas del emisor. En el tema que nos interesa, se ve en las características de las financiaciones subordinadas cierta capacidad de absorción de pérdidas, aunque lógicamente menor que el capital propiamente tal. Por ello, no basta con su configuración como un "crédito de último rango" (o "credit de dernier rang", como les denomina la doctrina francesa), sino que también será necesaria la determinación de ciertos requerimientos adicionales que permitan su mayor acercamiento al capital primario, especialmente en lo que se refiere a su estabilidad ${ }^{7}$. Por medio de la incorporación de la financiación subordinada al campo de los recursos propios de las entidades de crédito se logran varios efectos: $i$ ) ampliar el espectro de fuentes disponibles para que los bancos cumplan con los requerimientos de capital y solvencia; $i i)$ permitir al público en general el acceso a un instrumento de financiación adicional, con mayores niveles de retribución que la mayoría de los instrumentos de deuda; y iii) permitir un control indirecto por parte de los órganos reguladores dadas las señales del mercado en razón de las fluctuaciones de los créditos subordinados (la denominada "disciplina de mercado").

El presente artículo tiene por objeto explicar la lógica y el auge de las financiaciones subordinadas como alternativa de composición de los recursos propios de las entidades de crédito. A tales efectos, y encuadrado en la idea de promover la estabilidad del sistema financiero, revisaremos esta cuestión

\footnotetext{
${ }^{6}$ Onado, Marco, Aspetti economici e tecnici, en Portale, Giuseppe (director), La recapitalizzazione delle aziende, cit. (n. 5), p. 78.

${ }^{7}$ Portale, Giuseppe (director), La recapitalizzazione delle aziende, cit. (n. 5), p.
} 18. 
desde una perspectiva histórica, explicando la evolución de cada modelo, hasta llegar a una explicación de este aspecto del Derecho bancario chileno.

\section{BREVE REFERENCIA A LA EVOLUCIÓN HISTÓRICA DEL MODO DE COMPONERSE LOS RECURSOS PROPIOS DE LAS ENTIDADES DE CRÉDITO}

La exigencia de ciertos fondos mínimos se originó históricamente con la National Bank Act de 1863, que estableció esta suerte de requisitos para que la Office of the Comptroller of the Currency de los Estados Unidos de América otorgase licencias a bancos nacionales. En esta primera regulación, los requerimientos de capital estaban vinculados con el número de habitantes a ser cubierto por la entidad solicitante, de lo que se evidencia que su finalidad distaba de ofrecer un respaldo a la eficacia del sistema, sino más bien crear un parámetro objetivo para asegurar un tamaño suficiente para la cobertura interestatal. En todo caso, los datos empíricos dan cuenta de que durante el curso del siglo XIX, los niveles de capital de los bancos eran relativamente altos en relación con el riesgo de insolvencia al que se exponían los bancos estadounidenses ${ }^{8}$.

La situación cambió radicalmente con el colapso del sistema bancario norteamericano el año 1933, al menos, en dos sentidos: en primer lugar, se regularon las actividades que podían llevar a cabo los bancos a modo de controlar el riesgo implícito en tales operaciones; y, luego, se creó el Federal Deposit Insurance Corporation (FDIC) para otorgar una garantía básica a los depositantes. Surgieron también nuevos requerimientos de capital, pero no referidos aún a la estabilidad del sistema, sino impulsados por la necesidad del Estado de obtener recursos para la guerra: el cálculo del capital exigido se asocia a los niveles de riesgo de los activos, excluyendo, para efectos de cálculo, los instrumentos de deuda soberana? .

Hasta la década de los setenta, la estabilidad del sistema bancario se basaba en tres bases fundamentales ${ }^{10}$, a saber:

i) La red de seguridad ("safety net"), por la cual el órgano regulador -entre otras medidas- serviría de prestamista de último término a fin de asegurar la liquidez del sistema financiero. Esta asistencia, también deno-

${ }^{8}$ Lown, Cara - Peristani, Stavros - Robinson Kenneth, Capital Regulation and Depository Institutions, en BARTH, James - Brumbaugh, Dan Jr. - YAGo, Glenn (editores, Restructuring Regulation and Financial Institutions (Estados Unidos de América, Klower Academic Publishers, 2001), p. 44.

${ }^{9}$ Ibíd., p. 45.

${ }^{10}$ Uyemura, Dennis G. - van Deventer, Donald R., Financial Risk Management in Banking (Estados Unidos de América, Bankline, 1993), p. 27. 
minada "discount window", podía ser utilizada por bancos solventes, pero ilíquidos, permitiendo el acceso a fondos que no podría haber obtenido en el mundo privado.

ii) El sistema de protección a los depósitos mediante una garantía estatal mínima. Este mecanismo, si bien protege a los depositantes, no está exento de polémica, por cuanto presenta un problema de riesgo moral: al saber de la existencia del "seguro", las entidades bancarias pueden estar dispuestas a incurrir en actividades más riesgosas, lo que, a la larga, puede desequilibrar el sistema ${ }^{11}$.

iii) Las limitaciones a las actividades de los bancos. En Estados Unidos, la normativa específica que limitaba la participación de los bancos en mercados de alto riesgo se conoció como "Regulation Q". La forma de establecer las limitaciones, más que mediante normas prohibitivas, se efectuaba estableciendo un techo a los intereses que los bancos podían pagar en sus operaciones de captación (incluso con un cero por ciento).

Como indica Poveda: "Los primitivos coeficientes de garantía, o sus inversos, los 'gearing ratios', montados como consecuencia de la crisis de los años veinte y treinta, cumplieron razonablemente bien su misión mientras estuvieron acompañados de un cuadro complejo de restricciones institucionales a la libre competencia bancaria, mientras las entidades de crédito se atuvieron a sus actividades tradicionales, y mientras sus operaciones internacionales no fueron mucho más allá de unas relaciones de corresponsalía para canalizar pagos y transferencias de clientela"12.

Pero los años setenta probaron la ineficacia de los mecanismos de control establecidos por la OCC, el FDIC y el Federal Reserve Bank en las décadas anteriores, de lo que resultó el establecimiento del modelo de calificación ("rating") denominado CAMEL (acrónimo de "capital adequacy", "asset quality", "management", "earnings" y "liquidity") ${ }^{13}$. La doctrina económica hace referencia a que las regulaciones basadas únicamente en la limitación de actividades arriesgadas por parte de los bancos supusieron el surgimiento de una industria paralela dedicada únicamente a ellas, de lo cual resultó un empeoramiento del sistema en general. De ahí que se prefiriese su reemplazo por un sistema de estándares de capital mínimo a modo de mecanismo de control de riesgo ${ }^{14}$.

${ }^{11}$ Caesar, Camille M., Capital-Based Regulations and U.S. Banking Reform, en Yale Law Journal, 101 (1992) 7, p. 1.530.

${ }^{12}$ Poveda, Raimundo, La reforma de los coeficientes de solvencia, en Papeles de Economia Española, 44 (1990), p. 48.

${ }^{13}$ Que sustancialmente podemos traducir como "adecuación de capital”, "calidad de los activos", "administración", "ganancias" y "liquidez".

${ }^{14}$ Uyemura, D. - van Deventer, D., cit. (n. 10), pp. 27 y 28. 
El trato inicial al capital de vigilancia de los bancos fue, más bien, prudencial, modelo cuyo punto de quiebre fue la crisis de inicios de los años ochenta. La internacionalización de los bancos, la creación de instrumentos que escapaban del poder regulatorio de las entidades de vigilancia, el cruce entre las actividades bancarias y bursátiles, entre otros, fueron generando legítimas dudas respecto a la calidad de los activos del banco y a las herramientas con las que contaban las autoridades de vigilancia para su fiscalización ${ }^{15}$. Como factores externos, Tapia agrega el "grado creciente de riesgo vinculado al desarrollo de la misma actividad bancaria, por grandes crisis sectoriales, por discontinuidades coyunturales y por situaciones continuadas de tensiones inflacionistas y de inestabilidad en los tipos de cambio, junto al descenso de la calidad de los créditos" ${ }^{16}$. Llegada la crisis, se comprobaron dos extremos: la inexactitud del enunciado de que "los bancos no pueden quebrar" (el clásico "too big to fail") y de que no existían mecanismos legales suficientes para robustecer la estructura patrimonial de las entidades de crédito, cuestión que se hace más patente en las estructuras no corporativas, como en el caso de las cajas de ahorro europeas ${ }^{17}$.

Por su parte, y debido al proceso de globalización e internacionalización de las entidades financieras - patente a partir de los ochenta-, Estados Unidos presionó para la creación de estándares uniformes de requerimientos de capital, para no perjudicar competitivamente a la banca nacional ante regulaciones extranjeras que no contuviesen exigencias similares ${ }^{18}$. De hecho, bien puede decirse que la ausencia de controles efectivos por parte de las autoridades de vigilancia a inicios de tal década se justificaba como un intento de no quitar competitividad a los bancos nacionales frente a la banca extranjera ${ }^{19}$. Por tanto, la pregunta se resumía en quién disparaba primero, tomando en cuenta que el disparo estaba dirigido a la industria nacional. De

${ }^{15}$ Caesar, Camille, cit. (n. 11), p. 1.532.

${ }^{16}$ Tapia Hermida, Alberto Javier, La financiación externa de las cajas de ahorro, en particular las obligaciones subordinadas y las cuotas participativas, en Revista de Derecho Bancario y Bursatil, 43 (1991), p. 690.

${ }^{17}$ Onado, Marco, cit. (n. 6), p. 76.

${ }^{18}$ Un primer logro hacia la unificación se logró mediante el acuerdo entre el Bank of England y las entidades supervisoras norteamericanas (Office of the Comptroller, Federal Reserve y el Federal Deposit Insurance Corporation) para la adecuación de capital de las entidades financieras con actividades internacionales. Pese a que los acuerdos fueron alcanzados en marzo de 1986, y reflejados en el documento denominado: "Agreed proposal of the United States federal banking supervisory authorities and the Bank of England on primary capital and capital assesment" (publicado el 8 de enero de 1987), éstos nunca fueron llevados a efectos, pero sirvieron de impulso para los acuerdos del Comité de Basilea.

${ }^{19}$ CaEsar, Camille, cit. (n.11), p. 1.530. 
ahí la necesidad de uniformidad, base de los Acuerdos de Basilea alcanzados en 1988 por parte de los organismos regulatorios y bancos centrales del llamado "Grupo de los Diez". Dejamos aquí esta breve referencia a la evolución histórica en cuanto los hitos siguientes serán revisados desde la perspectiva de los modelos de reconocimiento de las financiaciones subordinadas como parte de los recursos propios de las entidades de crédito.

\section{LAS FINANCIACIONES SUBORDINADAS COMO COMPLEMENTO DE LOS RECURSOS PROPIOS DE LAS ENTIDADES DE CRÉDITO}

La inclusión de las financiaciones subordinadas como complemento de los recursos propios de las entidades de crédito no fueron, en su momento, nada pacíficas. Si bien es cierto que en situaciones de insolvencia su comportamiento se asemejaría al de los recursos propios primarios, la crítica se refería principalmente al hecho de que no pueden ser utilizadas para absorber pérdidas en otros supuestos ${ }^{20}$. La asimilación debe estar limitada, entonces, por tres características propias de la financiación subordinada: por su carácter de deuda, por su actuación únicamente en situaciones de crisis extrema, y por tratarse normalmente de instrumentos de renta fija. Como agrega Onado, las financiaciones subordinadas implican una carga financiera con independencia de la obtención de beneficios netos de la empresa, no pudiendo ser utilizadas para absorber las pérdidas corrientes de tipo patrimonial, sino sólo entran en juego cuando el patrimonio ya se ha perdido ${ }^{21}$.

Superada la polémica, se establecen una serie de restricciones para que las financiaciones subordinadas puedan ser computadas. Cabe concluir, entonces, que tales limitaciones tienen como principal motivación el acercar su comportamiento -hasta donde sea posible- al de los recursos propios primarios, reconociéndoles solamente un carácter "complementario", en el sentido de "no sustitutivo", del capital. Sin embargo, la regulación debe enmarcarse en un límite de razonabilidad, puesto que restricciones demasiado graves pueden desincentivar su colocación habida cuenta de la ausencia de demanda ${ }^{22}$. Nadie adquirirá un instrumento de deuda en la certeza que éste no podrá ser pagado, no sólo por la incapacidad del deudor, sino también por la temerosa mano del legislador.

En el sistema norteamericano, la emisión de deuda subordinada por parte de las entidades bancarias se inicia a fines de los años setenta y en los

\footnotetext{
${ }^{20}$ Zancada Peinado, Fermín, Los ratios de medición de solvencia, consideración especial de las entidades de depósito y la reciente reforma en España, en Papeles de Economía Española: Suplementos sobre el Sistema Financiero, 13 (1986), p. 16.

${ }^{21}$ Onado, Marco, cit. (n. 6), p. 87.

${ }^{22}$ Zancada Peinado, cit. (n. 20), p. 16
} 
ochenta, impulsados por el reconocimiento que se le da a la financiación subordinada como integrante de los fondos propios para fines de supervisión federal. La deuda subordinada no fue creación del sector financiero, pero fue en este ámbito donde se empezó a estructurar la idea de los "subordinated convertible debentures" (títulos de deuda subordinada convertibles en acciones). Conforme nos indica Schneider, la razón de la convertibilidad se encontraba en obtener una rebaja en la tasa de interés, justificada porque el adquirente del título está más interesado en el potencial aumento de valor de las acciones de la sociedad financiada que en la obtención de una tasa de interés incrementada por el mayor riesgo asumido ${ }^{23}$.

Sin embargo, cabe advertir que el aumento de la tasa de interés en la emisión de las financiaciones subordinadas por parte de las entidades de crédito puede ser más teórico que real. La mayor retribución depende del mayor riesgo asumido por el titular de las obligaciones subordinadas. No obstante, en el campo de las entidades de crédito, ese mayor riesgo tiende a ser morigerado por una multitud de factores económicos y jurídicos. Por de pronto, todas las medidas destinadas a la protección del sector bancario (el ya referido "security net") y el establecimiento de remedios paraconcursales para evitar su quiebra hacen que el adquirente de la obligación subordinada, psicológicamente, piense que el riesgo es extremadamente bajo ${ }^{24}$. Esta afirmación, sin embargo, debe ser actualmente matizada, como se comprueba por la reciente crisis económica. Así, se ha llegado a indicar que el mercado de las financiaciones subordinadas ha sido "torpedeado" por Lehman Brothers (cuarto banco de inversión de los Estados Unidos de América), "haciendo que sus titulares se enfrenten a la realidad de la quiebra de las entidades financieras" 25 .

\section{Modelos De Regulaciones específicas}

DE LAS FINANCIACIONES SUBORDINADAS

EN EL ÁMBITO DE LAS ENTIDADES DE CRÉDITO

Aunque existen varios modelos de regulación de las financiaciones subordinadas típicas, del estudio que sigue se advierte cómo existe entre ellos

${ }^{23}$ SchneIder, Uwe S., Finanziamenti subordinati come capitale proprio a fine di vigilanza negli Stati Uniti, en PORTALE, Giuseppe (director), La recapitalizzazione delle aziende, cit. (n. 5), p. 234. Sobre las ventajas económicas de la deuda convertible como ejemplo de los "híbridos financieros", puede consultarse a MCCORMICK, Roger - Creamer, Harriet, Hybrid Corporate Securities (Londres, Sweet \& Maxwell, 1987), pp. 40-41.

${ }^{24}$ Sobre el particular, TApia Hermida, Alberto Javier, cit. (n. 16), pp. 723 y 724.

${ }^{25}$ En la revista Euroweek, 1.073 (de 26 de septiembre de 2008), p. 71. 
una fluida comunicación. Así, hay un innegable vínculo entre los primeros modelos ofrecidos por el Comité de Basilea, las Directivas comunitarias de 1989 y la regulación chilena. Así también hay similitudes evidentes entre los acuerdos de "Basilea II" y las Directivas comunitarias de 2006.

Si bien se hará evidente que el ordenamiento jurídico chileno se ha basado íntegra y exclusivamente en las directrices de los acuerdos del Comité de Basilea de 1988, hemos preferido su estudio de modo separado a efectos de poder profundizar algo más en sus especificidades regulatorias. De ahí que este apartado se referirá únicamente a los modelos generales y no a regulaciones específicas.

\section{Modelos basados en el riesgo de crédito.}

a) El modelo de "Basilea I". El Comité de Basilea para la Supervisión Bancaria -dependiente del Bank for International Settlements (BIS)- ha publicado varios documentos que dan cuenta de diversos modelos para soportar y tratar los riesgos del mercado financiero. Por ello debemos diferenciar varias etapas que, sucesivamente, han ido perfeccionando la normativa, enfrentándose a los nuevos riesgos que implica la innovación financiera. El mundo, por supuesto, no es el mismo que el de los años ochenta.

El primer modelo -enunciado en los "Acuerdos de Basilea" de 1988 (actualmente conocido como "Basilea I") ${ }^{26}$ - se centró únicamente en el denominado "riesgo de crédito", referido posibilidad de que las colocaciones realizadas por el banco resulten impagas, sea por simple morosidad o por el deterioro de las capacidades patrimoniales del deudor. Esta aproximación reconocía abiertamente que se trataba de una normativa incompleta, en el sentido que no alcanzaría a cubrir todas las contingencias del sistema bancario $^{27}$. Pero se asumió así en tanto se trataba de un primer paso, sopesando que es éste el riesgo que afecta con más fuerza al sistema financiero.

"Basilea I" propuso enfrentar este riesgo clasificando los activos financieros conforme a su nivel de riesgo implícito y exigiendo un capital mínimo cuyo monto estaría determinado en razón del valor de los activos financieros ya clasificados (ocho por ciento). Pero la exigencia del capital mínimo requería de la determinación de los diferentes instrumentos necesarios para su concreción, de lo que surgía la clasificación de los recursos disponibles en capital propiamente tal ("core capital", "basic equity" o "tier 1") y capital

\footnotetext{
${ }^{26} \mathrm{El}$ texto de los Acuerdos de Basilea de 1988, denominado "International Convergence of Capital Measurement and Capital Standards" (en adelante, también "Basilea I") se encuentra disponible en http://www.bis.org/publ/bcbs04a.pdf?noframes=1 (consultada el 8 de marzo de 2010).

${ }^{27}$ Borroni, Mariarosa, Prestiti subordinati e "debt capital" nelle banche Italiane (Roma, Bancaria, 2006), p. 44.
} 
suplementario ("supplementary capital" o "tier 2") 28 . A este respecto, Fernández del Pozo daba cuenta que: "La novedad revolucionaria en cuanto a la definición del capital regulatorio consistió en la constatación de la diferente calidad de los recursos propios computables en atención a la mayor o menor disponibilidad de los mismos para la cobertura de los riesgos y para garantizar la continuidad empresarial" ${ }^{\prime 29}$. En suma, la razón de ser de esta distinción se traducía en los límites establecidos para el segundo tramo. Así, como límite genérico, se definió que el capital suplementario no podía superar los recursos obtenidos a modo de "core capital", además del establecimiento de restricciones específicas para cada uno de los instrumentos.

La financiación subordinada surgió entonces como uno de los elementos a tener en cuenta para la constitución del capital secundario ${ }^{30}$. El Comité estaba consciente de las deficiencias técnicas del instrumento -especialmente su fecha de vencimiento e incapacidad de absorber pérdidas fuera de los supuestos de liquidación- justificando así el requerimiento de ciertas cláusulas adicionales y las limitaciones específicas en cuanto a su monto. Sobre el particular, este primer modelo daba cuenta de ciertas características que se mantienen hasta la actualidad, de manera que sólo las referiremos para su posterior análisis: $i$ ) los fondos debían encontrarse completamente desembolsados; ii) no podían encontrarse garantizados, sino que debían subordinarse al pago del resto de las obligaciones de la entidad; $i i i$ ) debían tener un vencimiento de al menos cinco años; y $i v$ ) su contabilización debía sufrir una reducción del veinte por ciento en sus últimos cinco años de vigencia. Respecto a sus límites específicos, los montos obtenidos vía financiación subordinada no podrían superar el cincuenta por ciento de los recursos calificados como capital básico.

Pero el modelo original de "Basilea I" también incluía otra fórmula de financiaciones subordinadas: los híbridos financieros calificables como "deuda perpetua”. En cualquier caso, la asimilación de esta clase de instrumentos a los recursos propios de los bancos, incluso como capital primario, tuvo su origen en Inglaterra. La historia comenzó con la emisión de deuda perpetua (por un

${ }^{28}$ CAESAR, Camille, cit. (n. 11), p. 1.539, demuestra cómo el sistema de dos tramos en la conformación del capital para fines regulatorios, si bien uniforma los criterios divergentes de los diferentes países involucrados, otorga una mayor flexibilidad al sistema.

${ }^{29}$ Fernández del Pozo, Luis, Las participaciones preferentes (Cizur Menor, Thomson Civitas, 2005), p. 35.

${ }^{30}$ En "Basilea I", la referencia a los instrumentos de deuda perpetua y subordinada es más bien incidental. Se admite su asimilación como capital secundario conforme a su estructuración por el Banco de Inglaterra, al tiempo que se destaca su posibilidad de absorber pérdidas sin necesidad de proceder a la liquidación de la entidad de crédito. 
monto de quinientos millones de dólares) por parte del National Westminster Finance B.V. en 1984. Pero el hito a destacar -nos informa Fernández del Pozo- se dio ese mismo año, cuando el Bank of England, "dentro de su diseño de política de supervisión de la solvencia de las entidades de crédito bajo su jurisdicción, redescubre el viejo instrumento de la deuda perpetua [...]. Este pronunciamiento administrativo sigue una práctica intensísima de emisiones. El éxito del nuevo instrumento es un preludio de lo que luego vendrá en la regulación adoptada en "Basilea I" y en la Directiva 299/89/ CEE" 31 . Al efecto, y conforme se precisó en el marco de las negociaciones con Estados Unidos para la uniformidad de los requerimientos de capital (en marzo de 1986), su contabilización requería que la deuda fuese subordinada, perpetua, sólo redimible a voluntad del emisor y con autorización del Banco de Inglaterra, y automáticamente convertible en acciones preferentes en caso de pérdidas ${ }^{32}$. En el análisis de los requisitos establecidos por "Basilea I" (y, luego, por la normativa comunitaria), veremos que sólo se excluyó este último elemento, aunque se reemplazó por la posibilidad de postergar el pago de capital e intereses para el mismo evento de pérdidas ${ }^{33}$.

Siguiendo el modelo inglés, "Basilea I" dispuso que estos instrumentos podían ser contabilizados como capital secundario siempre que: $i$ ) no se encontrasen garantizados, sino subordinados al resto de los acreedores; $i$ ) los fondos estén completamente desembolsados; iii) no pudiesen rescatarse a requerimiento de su titular ni sin la autorización previa de la autoridad de vigilancia; $i v$ ) pudiesen participar en las pérdidas sin necesidad de proceder a la liquidación de la entidad; $y v$ ) admitiesen la posibilidad de postergar el pago de capital e intereses para el caso que las utilidades de la entidad no pudiesen soportar el pago. Sin embargo, una diferencia con la financiación subordinada propiamente tal podía observarse a nivel de sus límites de computabilidad toda vez que no tenía una restricción específica, sino sólo la limitación general aplicable a todos los instrumentos de capital suplementario. Ello se justificaba en que, por su calidad de deuda perpetua y su participación en las

${ }^{31}$ Fernández del Pozo, Luis, cit. (n. 30), p. 19.

${ }^{32}$ Fernández del Pozo, Luis, El fortalecimiento de recursos propios (Madrid, Marcial Pons, 1992), pp. 296-297. El requisito de la conversión en acciones fue posteriormente flexibilizado, nos informa Fernández del Pozo, Luis, cit. (n.30), p. 19, de modo que se admitió una cláusula por la cual el obligacionista sólo fuera "considerado como" un accionista preferente, en el sentido de tener derecho a ser reembolsado antes que el resto de los accionistas ordinarios.

${ }^{33}$ De hecho, McCormick, Roger - Creamer, Harriet, cit. (n. 24), p. 57, comentan que fue precisamente el requisito de conversión automática el que hizo que el régimen de las financiaciones perpetuas propuesto por el Bank of England fuera percibido como demasiado estricto por la práctica financiera. 
pérdidas previo a la liquidación de la entidad de crédito, se asemejaba con mayor fuerza a los caracteres del capital primario.

b) Modelos comunitarios europeos bajo el influjo de "Basilea I". La unidad del mercado europeo también pasaba por la actividad financiera. Así, se previó la unificación de los criterios para la creación y actividad de las entidades de crédito de manera de fomentar su competencia y no perjudicarles en razón de exigencias más onerosas que en otros países comunitarios. Esta preocupación se manifestó primeramente en la Directiva 77/780/CEE, de 12 de diciembre de 1977, dirigida a la coordinación de las disposiciones legales, reglamentarias y administrativas referentes al acceso a la actividad de las entidades de crédito y a su ejercicio ${ }^{34}$.

Respecto al tema que nos interesa, el artículo 3 de la citada Directiva dispuso que las entidades de crédito debían obtener una autorización estatal para el ejercicio de sus actividades, sujetándose, entre otros, al requisito de contar con un mínimo suficiente de fondos propios y permitiendo, en su artículo 8.d), la cancelación de dicha autorización de existencia si la entidad dejase de contar con tales recursos mínimos. Pero, a pesar de este intento unificador, esta Directiva no señaló la fórmula de cálculo de los fondos propios mínimos, a la vez que les definió como: "el capital propio de la entidad de crédito, comprendiendo los elementos que le son asimilables en virtud de las reglamentaciones nacionales" (artículo 1). Pero este punto no es de criticar sin detenerse que el propio considerando tercero señalaba que "no siempre es posible crear mediante una sola directiva las condiciones reglamentarias requeridas para un mercado común de las entidades de crédito; que es preciso por tanto proceder en etapas sucesivas..."

En razón de lo anterior, la constitución de los fondos propios de las entidades de crédito fue motivo para la promulgación de la Directiva 89/299/ CEE, de 17 de abril de 1989, la cual consideraba que los recursos de las entidades de crédito podían servir para absorber las pérdidas no cubiertas por un volumen suficiente de beneficios y que constituían, además, un criterio importante para que las autoridades competentes evaluasen la solvencia de las entidades de crédito $^{35}$. La inspiración de esta normativa en "Basilea I" es evidente, si bien su propósito particular es la armonización de los diversos sis-

${ }^{34} \mathrm{El}$ texto de la citada directiva se encuentra disponible en: http://www.cnmv.es/ Portal $/ \sim /$ verDoc.axd?sParams $=515 \& s$ TipoDoc $=1 \& s$ CodDoc $=$ GCON (consultada el 8 de marzo de 2010).

${ }^{35}$ La referida directiva fue derogada por la Directiva 2000/12/CEE, de 20 de marzo de 2000, relativa al acceso a la actividad de las entidades de crédito y a su ejercicio, cuyos artículos 35.2 y 36.3 mantuvieron la regulación existente sobre financiaciones subordinadas, sin introducir en ella cambios sustanciales. A su vez, la señalada normativa fue derogada por la Directiva 2006/48/CE, la que se analizará en extenso a continuación, 
temas europeos ${ }^{36}$. Por ello, no tenían el carácter de una mera recomendación, sino que eran de recepción obligatoria para todos los Estados miembros ${ }^{37}$. Sin embargo, no debe pensarse que la idea del fortalecimiento de los recursos propios de las entidades de crédito ni el reconocimiento de las financiaciones subordinadas a tales efectos fueron introducidos por la señalada directiva. Al contrario, existían multitud de regulaciones en el viejo continente, siendo necesario - a efectos de consolidar un mercado unitario- el establecimiento de un criterio común.

Pero esta finalidad sólo fue parcialmente lograda. En efecto, el considerando quinto señalaba que la "definición enunciada en la presente Directiva contiene un máximo de elementos y cantidades limitativas, dejándose al poder discrecional de los Estados miembros la utilización de la totalidado de una parte de dichos elementos y la fijación de limites inferiores a dichas cantidades limitativas”. Aún así, el artículo 2.2 todavía daba cuenta del interés en la armonización, disponiendo que: "No obstante, éstos deberán contemplar el logro de una mayor convergencia con vistas a una definición común de los fondos propios". Se propuso seguir una distinción cercana a la de "Basilea I", clasificando los recursos en "fondos propios de base" y "fondos propios complementarios". Entre estos últimos, y a los efectos que nos interesan, se reconocieron las "financiaciones perpetuas" y los "préstamos subordinados".

El artículo 3.2 incluía aquellos títulos de duración indeterminada y los demás instrumentos similares que cumplan ciertos requisitos, entre los cuales estaba el que "los créditos del acreedor contra la entidad de crédito deban estar subordinados en su totalidad a los de todos los acreedores no subordinados." Otras características exigidas fueron: $i$ ) que no pudiesen ser reembolsados a petición del portador o sin el acuerdo previo de la autoridad de vigilancia; $i$ ) que el contrato de emisión concediese a la entidad de crédito la posibilidad de diferir el pago de los intereses de la deuda; iii) que los documentos que regulasen la emisión de los títulos estableciesen que la deuda y los intereses no pagados pudiesen absorber pérdidas, dejando a la entidad de crédito la posibilidad de seguir operando; y $i v$ ) que únicamente se tuviesen en cuenta los importes efectivamente pagados.

aun cuando el régimen de los préstamos subordinados no fue especialmente alterado a este respecto.

${ }^{36}$ A juicio de Fernández del Pozo, Luis, cit. (n. 30), pp. 35-36, la incorporación del "sistema de Basilea" en el Derecho comunitario se produce en tres áreas: $i$ ) la adecuación del capital de las empresas de inversión y las entidades de riesgo; ii) el establecimiento de un coeficiente de solvencia de las entidades de crédito; y iii) la supervisión de conglomerados financieros formados por entidades de crédito, empresas de seguro y empresas de inversión.

${ }^{37}$ Borroni, Mariarosa, cit. (n. 28), pp. 60 y 61. 
Por su parte, el artículo 4.3 reconocía a los préstamos subordinados como parte de los recursos mínimos, siempre que se sujetaren a las siguientes características: $i$ ) que existiesen acuerdos vinculantes con arreglo a los cuales, en caso de quiebra o de liquidación de la entidad de crédito, tales préstamos ocupasen un rango inferior a los créditos de todos los demás acreedores y no se reembolsasen hasta que se hubiesen pagado todas las demás deudas vigentes en ese momento; ii) que únicamente se tuviesen en cuenta los fondos efectivamente desembolsados; $i i i$ ) que dichos fondos tuviesen un vencimiento inicial de al menos cinco años o que, no teniendo fijada una fecha de vencimiento, tuviesen estipulado un preaviso de cinco años para su rescate, salvo en el caso de que hubiesen dejado de considerarse fondos propios o si se exigiese formalmente la autorización previa de las autoridades competentes para su reembolso anticipado; iv) que la cuantía hasta la cual pudiesen considerarse fondos propios fuese objeto de una reducción gradual durante al menos los cinco años anteriores a la fecha de vencimiento; y $v$ ) que el contrato de préstamo no incluyese cláusulas que estipulasen que, en determinadas circunstancias distintas de la liquidación de la entidad de crédito, la deuda debiese reembolsarse antes de la fecha de vencimiento acordada.

La Directiva 89/647/CEE, de 18 de diciembre de 1989, sobre el coeficiente de solvencia de las entidades de crédito, complementaba la anterior, dando cuenta que el establecimiento de tal coeficiente (de un ocho por ciento) desempeña un papel fundamental en la supervisión de las entidades de crédito. Así, su artículo 3.1 disponía que: "El coeficiente de solvencia contemplado en los apartados 2 a 7 expresa la proporción existente entre los fondos propios definidos en el artículo 4 y los activos y cuentas de orden con riesgo ponderado con arreglo al artículo 5." Por supuesto, la definición de los fondos propios, que constituía el numerador de la proporción, hacía referencia a la Directiva 89/299/CEE, que ya hemos estudiado.

\section{Las revisiones del modelo original a modo de ampliación de riesgos} cubiertos.

a) Primeras modificaciones a "Basilea I" y el surgimiento de "Basilea II". Todo el modelo original de "Basilea I" debió ser modificado y complementado en enero de 1996 en atención a la constatación de la creciente importancia de un nuevo riesgo: el "riesgo de mercado". Se refiere éste al efecto que produce en la variación de las tasas de interés y los tipos de cambio en los instrumentos de deuda tomados por la entidad de crédito ${ }^{38}$. Así, por medio del documento denominado "Amendment to the capital

\footnotetext{
${ }^{38}$ Sappiddem, Razeen, The Regulation of Credit, Market and Operational Risk Management Under the Basel Accord, en Journal of Business Law, 1 (2004), p. 64.
} 
accord to incorporate market risks", el Comité de Basilea estableció las bases para el control de esta nueva contingencia, nuevamente mediante el establecimiento de un capital mínimo en referencia a los activos ponderados por riesgo ${ }^{39}$. Para estos efectos, se incorpora un tercer tramo ("weak capital" o "tier 3"), constituido por financiación subordinada a corto plazo. A esta clase de financiación se le reconoció, aunque de manera muy limitada, una cierta capacidad de mejorar la adecuación patrimonial de la banca en tanto contribuye a aligerar el peso del riesgo de mercado en el capital básico ${ }^{40}$.

Los requisitos específicos de esta financiación subordinada de tercer tramo eran que: $i$ ) los fondos debían encontrarse completamente desembolsados; ii) no podían encontrarse garantizados, sino que debían subordinarse al pago del resto de las obligaciones de la entidad; $i i i)$ debían tener un vencimiento de al menos dos años; iv) no podían ser reembolsados anticipadamente sin la autorización de la autoridad de vigilancia; $\mathrm{y} v$ ) debían prever una cláusula de "lock-in", por la cual la autoridad de vigilancia podía ordenar la suspensión del pago del principal y de los intereses, si en virtud de tal pago el banco no alcanzase a cumplir con los requerimientos de capital. Respecto a sus límites específicos, los montos obtenidos vía esta financiación subordinada especial no podían superar el doscientos cincuenta por ciento de los recursos calificados como capital básico necesarios para la cobertura del riesgo de mercado. A su vez, la suma de los fondos calificados como "tier 2 y "tier 3 " no podían exceder los montos del tramo 1 , restricción que, en todo caso podía ser modificada por las autoridades nacionales.

La evolución de los mercados financieros y de la forma en la que las entidades de crédito funcionan en ellos provocó la necesidad de dar una nueva mirada a los requerimientos de capital. El riesgo de crédito - materia de "Basilea I"- se quedó corto ante otras tantas contingencias que las entidades supervisoras y el mercado avizoran en el horizonte, considerando que la identificación del riesgo de mercado en 1996 tampoco fue suficiente para asegurar la fortaleza del sistema ${ }^{41}$. Así, ya en 1999 se anticipa la creación de un nuevo marco regulatorio, mediante la publicación de una consulta ("consultive paper") por parte del Comité de Basilea, todavía focalizando la supervisión desde la idea única-aunque mejorada-de los requerimientos de adecuación de capital. La propuesta original no fue exitosa, de modo que fue reformulada en el año 2001, proponiendo por primera vez una estructura

\footnotetext{
${ }^{39}$ El texto de las Modificaciones a los Acuerdos de Basilea de 1996 se encuentra disponible en: http://www.bis.org/publ/bcbs24.pdf?noframes=1 (consultada el 8 de marzo de 2010).

${ }^{40}$ Borroni, Mariarosa, cit. (n. 28), p. 49.

${ }^{41}$ Wu, Eric, Basel II: A Revised Framework, en Annual Review of Banking and Financial Law, 24 (2005), p. 152.
} 
basada en tres pilares: los requerimientos regulatorios de capital mínimo, el proceso del examen supervisor y la disciplina de mercado. La innovación fue máxima, y llega a un nivel de complejidad que supera por mucho los incipientes intentos de 1988. Ello dado que los "Nuevos Acuerdos de Basilea" (conocidos como "Basilea II") han pretendido afrontar un catálogo más extenso de contingencias, aunque siempre en forma de listado abierto y sujeto a revisión ${ }^{42}$. El mercado avanza demasiado rápido como para cerrar la puerta y entender que la tarea ha finalmente concluido.

El propio documento explicativo de "Basilea II" da cuenta que: "El objetivo primordial del Comité al revisar el Acuerdo de 1988 ha sido establecer un marco que fortaleciera en mayor medida la solidez y estabilidad del sistema bancario internacional, manteniendo al mismo tiempo la necesaria consistencia para que la normativa de suficiencia" ${ }^{33}$. La nueva fórmula retiene ciertos elementos del acuerdo original, tales como el requerimiento de capital basado en el porcentaje (ocho por ciento) de los activos ponderados por riesgo, la estructura de análisis de los riesgos de mercado establecidos en 1996 y la configuración de los recursos propios ${ }^{44}$. Pero avanza en la identificación de nuevos riesgos (especialmente el denominado "riesgo operacional"), en la elaboración de dos nuevos pilares (los procedimientos de supervisión y la disciplina de mercado) y en el establecimiento de mecanismos alternativos para el cálculo de requerimientos de capital, entre otros.

Particularmente respecto a las financiaciones subordinadas, "Basilea II" resume todos los avances alcanzados a la época, incluyendo la referencia a sus diversas formas a efectos de su cómputo como recursos complementarios ("tier 2") o auxiliares ("tier 3"). La diferencia no se encuentra, por tanto, en su tipología, sino en los aspectos para los cuales pasan a tener importancia. Como indicábamos, "Basilea II" pretende enfrentar un abanico de riesgos bastante más amplio que el riesgo de créditos, y, en todos ellos, la conformación de los recursos propios forma parte de la ecuación. Una explicación particular de todas estas fórmulas, creemos, sobrepasa el interés del presente trabajo.

b) El nuevo giro de las directivas comunitarias europeas. Por su parte, la Directiva 93/6/CEE, de 15 de marzo de 1993, sobre la adecuación del capital de las empresas de inversión y las entidades de crédito, anticipándose a las modificaciones a "Basilea I" de 1996, incluyó un tercer tramo de recursos propios como forma de paliar el riesgo de mercado de

${ }^{42}$ SappideEM, Razeen, cit. (n. 39), p. 61.

${ }^{43} \mathrm{~A}$ la fecha, el texto más actualizado de los acuerdos de Basilea II datan del año 2006, y se encuentran disponibles en: http://www.bis.org/publ/bcbs128.pdf (consultada el 8 de marzo de 2010).

${ }^{44}$ Para una referencia comparativa entre "Basilea I" y "Basilea II", véase: Wu, Eric, cit. (m. 42), pp. 152-54. 
las entidades de crédito. Este tramo estaba compuesto principalmente por préstamos subordinados que cumpliesen con las siguientes características: $i$ ) que tuviesen una duración inicial de al menos dos años; ii) que hubiesen sido plenamente desembolsados; iii) que el contrato de préstamo no contuviese cláusulas que establecieren que, en determinadas circunstancias, salvo en el caso de liquidación de la entidad, la deuda pudiese ser amortizada antes de la fecha de amortización convenida, a no ser que las autoridades competentes así lo autorizasen; y $i v$ ) que su principal e intereses no pudiesen ser pagados si producto de tal desembolso los fondos propios de la entidad se situasen por debajo del cien por ciento de las necesidades globales de capital de la entidad.

Pero más relevante aún, a inicios del presente siglo, Europa sintió la necesidad de adecuar todo el sistema en vigor en relación con la conformación de los recursos propios de las entidades de créditos, habida cuenta especialmente de la diversificación de los riesgos que afectan este mercado. La Directiva 2000/12/CE, de 20 de marzo de 2000, relativa al acceso a la actividad de las entidades de crédito y a su ejercicio, derogó las anteriores disposiciones estableciendo un sistema menos discrecional para los Estados miembros ${ }^{45}$. No se modificaron, en términos generales, las exigencias de las financiaciones perpetuas (artículo 35.2) y de los préstamos subordinados (artículo 36.3), pero sí se dio cuenta "que los criterios empleados para determinar la composición de los fondos propios no deben quedar únicamente en la apreciación de los Estados miembros. La adopción de normas de base comunes será altamente beneficiosa para la Comunidad, al evitar distorsiones de la competencia y al fortalecer simultáneamente el sistema bancario de la Comunidad [...]" (considerando trigésimo cuarto).

No nos hemos referido en extenso a tales regulaciones, por cuanto hemos preferido hacerlo a la luz de lo dispuesto en la norma comunitaria en vigor. Así, la Directiva 2006/48/CE, de 14 de junio de 2006, relativa al acceso a la actividad de las entidades de crédito y a su ejercicio, adecúa la normativa a los avances ya planteados por "Basilea II", tratando de los préstamos su-

${ }^{45}$ Objetivo que, nuevamente, no es logrado en tanto su considerando $35^{\circ}$ señala expresamente que: "La definición de "fondos propios" enunciada en la presente Directiva contiene un máximo de elementos y de cantidades limitativas, dejándose al poder discrecional de los Estados miembros la utilización de la totalidad o de una parte de dichos elementos y la fijación de limites inferiores a dichas cantidades limitativas". Por ello, BoRRONI, Mariarosa, cit. (n. 28), p. 68, concluye que la verdadera novedad de la Directiva 2000/12/CE fue el establecimiento de un modelo de adecuación de capital en base consolidada, sistema perfeccionado mediante la Directiva 2002/87/CE, de 16 de diciembre de 2002, relativa a la supervisión adicional de las entidades de crédito, empresas de seguros y empresas de inversión de un conglomerado financiero. 
bordinados del modo que resumimos a continuación. Pero considérese que aun cuando se pretende lograr una mayor armonización, eliminado de sus considerandos las referencias a la discrecionalidad de los Estados miembros para la determinación de los elementos que componen los fondos propios, cabe tener en cuenta que el artículo 61 dispone que: "El concepto de fondos propios definido en las letras a) a b) del artículo 57 incluirá un máximo de elementos y de cantidades. La utilización de dichos elementos o el establecimiento de limites inferiores, asi como la deducción de otros elementos distintos de los enumerados en las letras i) a r) del articulo 57, se dejarán a la discreción de los Estados miembros".

El artículo 57 de la citada directiva dispone que los fondos propios de las entidades de crédito están compuestos, entre otros, por " $f$ ) los demás elementos, a efectos del artículo 63" (que incluye la posibilidad de emisión de deuda perpetua y subordinada) y por " $h$ ) [...] los préstamos subordinados mencionados en el apartado tres del artículo 64". En consecuencia, debemos detenernos en uno y otro supuesto.

En primer lugar, el artículo 63.2 admite que los Estados miembros acojan como recurso complementario las "financiaciones perpetuas". La configuración específica de este instrumento, aunque subordinado, ha llevado a Portale a señalar que se trata de una figura autónoma, proponiendo un estudio separado ${ }^{46}$. No creemos que deba llegarse a este extremo: la cláusula de subordinación es la que permite su acercamiento a los recursos propios del deudor; el carácter irredimible beneficia la estabilidad del instrumento de forma tal de aprovechar de mejor modo tal asimilación ${ }^{47}$. Así, sus requisitos generales son: $i$ ) que no puedan ser reembolsados a petición del portador o sin el acuerdo previo de la autoridad competente; ii) que el contrato de emisión conceda a la entidad de crédito la posibilidad de diferir el pago de los intereses de la deuda ${ }^{48}$; iii) que los créditos del acreedor contra la entidad de crédito estén subordinados en su totalidad a los de todos los acreedores no subordinados; $i v$ ) que los documentos que regulen la emisión de los títulos establezcan que la deuda y los intereses no pagados puedan absorber pérdidas, dejando a la entidad de crédito la posibilidad de seguir operando ${ }^{49} ; \mathrm{y} v$ )

${ }^{46}$ Portale, Giuseppe, Prestiti subordinati e prestiti irredimibili (apunti), en Banca Borsa e Titoli di Credito, 46 (1996) 1, p. 2.

${ }^{47}$ Fernández del Pozo, Luis, cit. (n. 30), p. 33.

${ }^{48}$ La Directiva no señala la oportunidad en que la entidad de crédito puede ejercer esta facultad, aunque - por tradición y en atención a la lógica financiera del instrumento- debe tener lugar cuando se presente un escenario de pérdidas.

${ }^{49}$ Frase ésta que parece no ser lo suficientemente clara en cuanto a lo que realmente quiere exigir. Portale, Giuseppe, Prestiti subordinati, cit. (n. 46), p.16, haciendo referencia al antecedente de Basilea I, concluye que se refiere a su posibilidad de absorber 
que únicamente se tengan en cuenta los importes efectivamente pagados, cuestión evidente, por cuanto, si aún no han sido desembolsados, los montos no podrán ser contabilizados a efectos de cumplir el objetivo de los recursos propios: la absorción de pérdidas.

Los préstamos subordinados son tratados en el artículo 64.3 de la citada Directiva $^{50}$. Así, se exigen las siguientes características para efectos de su cómputo: $i$ ) únicamente deben tenerse en cuenta los fondos efectivamente desembolsados; $i$ ) deben tener un vencimiento inicial de al menos cinco años, pero, de no haber sido fijada la fecha de vencimiento de la deuda, los créditos afectados sólo serán reembolsables con un preaviso de cinco años, salvo en el caso de que hayan dejado de considerarse fondos propios o si se exigiere formalmente la autorización previa de las autoridades competentes para su reembolso anticipado; iii) que la cuantía hasta la cual puedan considerarse fondos propios fuese objeto de una reducción gradual durante al menos los cinco años anteriores a la fecha de vencimiento ${ }^{51}$; y iv) el contrato de préstamo no debe incluir cláusulas que estipulen que, en determinadas circunstancias distintas de la liquidación de la entidad de crédito, la deuda deba reembolsarse antes de la fecha de vencimiento acordada.

Adicionalmente, los préstamos subordinados -al igual que las financiaciones perpetuas- están sujetos a la idea de complementariedad. Ello porque los recursos obtenidos en razón de los mismos no son contabilizados de igual manera que el capital y las reservas de la entidad de crédito, sino que sujetos a ciertos límites genéricos señalados en el artículo 66 de la citada Directiva. Límites que, en cualquier caso, pueden ser modificados provisional y excepcionalmente por las autoridades competentes (artículo 66.4). No puede ser de otro modo dado que, aun cuando se establezcan cláusulas limitativas a su rescate anticipado o se estructuren como deuda perpetua, la financiación subordinada sigue siendo deuda, y, como tal, está destinada a su extinción ${ }^{52}$.

Se trata, por cierto, de límites genéricos, en el sentido de que no solamente

pérdidas sin que sea necesario recurrir a algún procedimiento de liquidación.

${ }^{50} \mathrm{La}$ referencia a los "préstamos subordinados" empleada por la Directiva no debe entenderse limitativo a una fórmula de endeudamiento en particular. Al contrario, creemos que debe hacer referencia a cualquier mecanismo que suponga la entrega de fondos por parte de terceros que no implique un aporte por vía asociativa. Supone lo anterior una cierta neutralidad instrumental, cuestión que supera la idea de la emisión de deuda únicamente mediante la fórmula de bonos subordinados.

${ }^{51}$ La Directiva no señala cómo debe procederse a dicha reducción en términos numéricos, sino sólo que debe efectuarse al menos los cinco años anteriores al vencimiento. Ha de suponerse una reducción proporcionalmente idéntica por los números de años faltantes, que, siendo generalmente de cinco años, supone entonces una reducción de veinte por ciento anual.

${ }^{52}$ Cesarini, Francesco, Aspetti funzionali e di mercato degli strumenti di ricapita- 
incluyen a los préstamos subordinados, sino que se aplican a la suma de otros instrumentos asimilados a fondos propios de las entidades de crédito, contenidos en las letras d) a h) o en las letras g) y h), según el caso, del artículo 57 de la Directiva. Pero sí cabe llamar la atención sobre que las financiaciones perpetuas, al estar tratadas en la letra f) del citado artículo, sólo son objeto de la limitación genérica a todos los recursos propios complementarios, mientras que las financiaciones subordinadas propiamente tales además son objeto de una limitación específica del cincuenta por ciento del capital básico. Ello, siguiendo los criterios expuestos en "Basilea I", se debe a la mayor semejanza de las financiaciones perpetuas al concepto económico del capital, especialmente por su estabilidad y posibilidad de absorción de pérdidas aún fuera de los supuestos de liquidación.

Finalmente, la importancia de las financiaciones subordinadas (perpetuas o no) a efectos de la citada Directiva puede resumirse en la idea de reforzar los fondos propios de la entidad de crédito para soportar una amplia gama de riesgos que afectan esta actividad económica. En razón de ello, se establecen requisitos de fondos propios mínimos (artículo 10.1) y los efectos de su disminución (artículo 10.5 y 17.1). Pero se utilizan principalmente para el cálculo del nivel mínimo de los fondos propios de la entidad (artículo 75), materia que debe ser complementada por la Directiva 2006/49/CE, de 14 de junio de 2006, sobre la adecuación del capital de las empresas de inversión y las entidades de crédito, distinguiendo los índices a cumplirse en relación con el riesgo de crédito, el riesgo de dilución, el riesgo de posición, el riesgo de liquidación, el riesgo de contraparte, el riesgo de tipo de cambio, el riesgo sobre materias primas y el riesgo operacional ${ }^{53}$; para el cálculo de los requisitos mínimos de fondos propios para el riesgo de crédito (artículos 75 y siguientes); para el cálculo de los requisitos mínimos de fondos propios para el riesgo operacional (artículos 102 y siguientes); para el cálculo y limitaciones de los grandes riesgos (artículos 106 y siguientes), relativos a los casos en que las entidades de crédito aumentan su riesgo en razón de la concentración de actividades con un solo cliente o con clientes relacionados entre sí; para el

lizzazione delle banche, en PORTAle, Giuseppe (director), La recapitalizzazione delle aziende, cit. (n. 5), p. 63.

${ }^{53}$ En la Directiva 89/299/CEE el coeficiente de garantía sólo respondía a la cobertura del denominado "riesgo de insolvencia", consistente en la posibilidad que los deudores de las entidades bancarias no pudieren cumplir con sus obligaciones. El modelo RAR ("risk asset ratio) impuesto por dicha directiva, como asimismo por los Acuerdos de Basilea de 1988, anticiparon que no se trataba de una solución completa y que, a la larga, debía también revisarse la cobertura de los otros riesgos ahora sí señalados en la Directiva 2006/49/CE. 
cálculo de las limitaciones a las participaciones cualificadas no financieras (artículos 120 y siguientes), etc.

Por su parte, la citada Directiva 2006/49/CE establece ciertas excepciones respecto al cómputo de los fondos propios de las entidades de inversión y entidades de crédito. Sobre el particular, el artículo 13.2 dispone que las autoridades competentes podrán permitir que las entidades que estén obligadas a cumplir las exigencias de capital calculadas con arreglo a los artículos 21 y 28 a 32 y los anexos I, y III a VI se acojan a una definición alternativa de fondos propios solamente para el cumplimiento de dichas exigencias. Así, mientras el artículo 21 se refiere a las necesidades de fondos propios de las entidades de inversión -que deben ser un equivalente de la cuarta parte de los gastos de estructura del ejercicio precedente-, los artículos 28 y 32 se relacionan con mecanismos especiales para la supervisión de las grandes exposiciones de las entidades haciendo excepción a los criterios generales establecidos en los artículos 106 y siguientes de la Directiva 2006/48/CE.

De este modo, se permite que, para efectos de los cálculos antes indicados, tales fondos propios estén integrados por una deuda subordinada especial, sujeta a los requisitos establecidos por el artículo 13.3 de la misma Directiva. Como veremos, renace en este punto la idea del tramo 3 (tier 3) impuesta por la Directiva 93/6/CEE y las modificaciones a "Basilea I" de 1996. Para estos efectos, la financiación subordinada deberá cumplir con los siguientes requisitos: $i$ ) tener una duración inicial de al menos dos años; $i i$ ) haber sido plenamente desembolsada; iii) carecer de cláusulas que establezcan que, en determinadas circunstancias, salvo en el caso de liquidación de la entidad, la deuda pueda ser amortizada antes de la fecha de amortización convenida, a no ser que las autoridades competentes así lo autoricen; $i v$ ) que ni el principal ni los intereses de esta deuda subordinada podrán ser pagados si con tal desembolso los fondos propios de la entidad se situasen por debajo del cien por ciento de las exigencias globales de capital de esa entidad; y $v$ ) que las entidades supervisadas deberán notificar a las autoridades competentes todas las amortizaciones de dichos préstamos subordinados, si con motivo de tales amortizaciones, los fondos propios de la entidad se situasen por debajo del ciento veinte por ciento de las exigencias globales de capital de la entidad.

Finalmente, en cuanto a un límite general, el artículo 13.4 dispone que en ningún caso la deuda subordinada podrá superar el ciento cincuenta por ciento de los fondos propios básicos destinados a cubrir las exigencias calculadas con arreglo a los artículos 21 y 28 a 32 y en los anexos I a VI, y únicamente podrá aproximarse a dicho importe en aquellas circunstancias específicas que las autoridades competentes consideren aceptables. 


\section{El Sistema CHILENo, ANCLADO EN “BASIleA I"}

\section{Descripción general del sistema:}

En Chile, la primera regulación sobre las financiaciones subordinadas encuentra sus raíces en la Ley $\mathrm{N}^{\circ} 18.818$, de 1 de agosto de 1989, que estableció normas destinadas a regularizar la situación de los bancos que habían sido intervenidos a raíz de la crisis económica experimentada entre los años 1982 y 1983 . Dicha ley trató de la subordinación en dos sentidos: primero, incorporó un nuevo artículo 15 a la Ley $\mathrm{N}^{\circ} 18.401$, de 26 de enero de 1985 , a efectos de regular las particulares circunstancias de los bancos que estaban sujetos a intervención; y, luego, conforme a las recomendaciones de "Basilea I", estableció la posibilidad de que los bancos e instituciones financieras emitieran bonos subordinados a efectos de poder computarlos como parte del patrimonio efectivo de la empresa, introduciendo un artículo 68 a la Ley general de bancos, actualmente artículo 55 del texto refundido contenido en el Decreto con fuerza de ley $\mathrm{N}^{\circ} 3$, de 19 de diciembre de $1997^{54}$.

Respecto al primer supuesto, el citado artículo 15 dispuso que: "los bancos $y$ sociedades financieras que tengan pendientes pactos de recompra de cartera con el Banco Central de Chile a que se refiere el artículo 10,podrán solicitar a éste la novación de todas las obligaciones que deriven de los contratos de compraventa de cartera, sustituyéndolas por una nueva obligación de carácter subordinado que se sujetará a lo previsto en este artículo" "55. Tales deudas subordinadas consistirían en obligaciones de plazo indeterminado, cuyo pago sólo se efectuaría con los excedentes del ejercicio anual, deducida la parte que correspondiese a

${ }^{54}$ Todavía no actualizada conforme a las directrices contenidas en Basilea II, aun cuando la SBIF ha planteado una "hoja de ruta" para su implementación, disponible en http://www.sbif.cl/sbifweb/servlet/Noticia?indice $=2.1 \&$ idContenido $=2731$ (consultada el 8 de marzo de 2010). Significa lo anterior que los bonos subordinados sólo tienen cabida en el segundo tramo de conformación de los recursos propios de la empresa (Tier 2) y que las cuestiones de "disciplina de mercado" no se encuentran suficientemente desarrolladas en el ámbito normativo, dada la falta de precisión en torno a la información que las entidades bancarias deben entregar al mercado.

${ }^{55}$ Téngase presente la explicación de UGarte Godoy, José Joaquín, Sobre la posibilidad de pactar que una obligación tenga el carácter de subordinada en el Derecho chileno, en Varas Braun, Juan Andrés - Turner Saelzer, Susan (coordinadores), Estudios de Derecho Civil: Código y Dogmática en el Sesquicentenario de la Promulgación del Código Civil. Jornadas Nacionales de Derecho Civil, Valdivia (Santiago, LexisNexis, 2005), pp. 378 ss.; sobre el particular, que se resume en que, cuando tuvo lugar la crisis económica de 1982 y 1983, los bancos más importantes del país entraron en graves dificultades financieras, de modo que debieron ser intervenidos de acuerdo a los términos de la Ley General de Bancos. Para evitar la crisis, se optó por que el Banco Central comprara las carteras de tales bancos intervenidos, con la obligación de los bancos comerciales de recomprarlas. 
las acciones preferentes. Además, no se computarían como pasivos exigibles de la entidad financiera, y, en caso que ésta se encontrase en situación de liquidación forzosa, se pagarían después de todas sus demás obligaciones, pero antes que los accionistas, de lo que deriva su carácter de subordinación general e incompleta ${ }^{56}$ El recurso a la deuda subordinada se justificaba en este caso ante la imposibilidad de que el Banco Central capitalizara la deuda a modo de acciones preferentes, para así liberar parte del pasivo de los bancos. Así, la alternativa encontrada lograba similares efectos, como si se tratare de acciones sin derecho a voto, pero con una obligación de pago diferido en el tiempo a cuando existieren utilidades del ejercicio.

Respecto al supuesto de los bonos subordinados, la normativa chilena no es demasiado profunda, manteniéndose - hasta la fecha- en los primeros avances del Comité de Basilea en 1988. Así, el artículo 55 de la Ley general de bancos, complementado por el capítulo 9-6 de la Recopilación Actualizada de Normas de la Superintendencia de Bancos e Instituciones Financieras (en adelante, SBIF), se dedican a configurar los requisitos generales de la financiación subordinada a efectos de su cómputo como "patrimonio efectivo" del banco, cuestión que es acogida parcialmente en el artículo 66 de la Ley general de bancos.

Conforme a la citada normativa, hemos de caracterizar las financiaciones subordinadas típicas en el ordenamiento jurídico chileno conforme a los siguientes parámetros:

a) Subordinación general e "incompleta": el carácter de deuda subordinada hará que, en caso de que la entidad emisora se encuentre en concurso de acreedores, esto es, en estado de liquidación forzosa, estos bonos se paguen después de los demás acreedores, incluidos los valistas. Sin embargo, y como analizaremos un poco más adelante, la regulación no sólo se sitúa en el evento de liquidación, sino que también señala el régimen aplicable a los bonos subordinados cuando el Directorio del banco emisor presente convenio a sus acreedores. En tal caso, una vez aprobado el convenio, los bonos subordinados serán capitalizados por el solo ministerio de la ley, hasta concurrencia de lo necesario para que la proporción entre el patrimonio efectivo y los activos ponderados por riesgo no sea inferior al doce por ciento.

b) Estabilidad: en esta materia se han se han seguido de cerca los planteamientos de "Basilea I", en términos que el plazo promedio de vencimiento de los bonos subordinados no puede ser inferior a cinco años, y que el cómputo de los mismos está sujeto a deducción de veinte por ciento por año durante sus últimos cinco años de vigencia ${ }^{57}$. De igual manera, se establece la prohibición

${ }^{56}$ Véase: Ugarte Godoy, José Joaquín, cit. (n. 56), p. 379.

${ }^{57}$ Para la determinación del plazo promedio, la sección 3.2 del capítulo 9.6 de 
genérica que impide el pago o rescate anticipado de los títulos subordinados por parte de la entidad bancaria, negando asimismo validez a las cláusulas que pudieren implicar el pago anticipado de todo o parte de los bonos.

c) Excepcionalidad: a diferencia de la neutralidad instrumental presente en las recomendaciones de "Basilea I" y en la regulación comunitaria, la Ley general de bancos establece un único instrumento por medio del cual obtener el beneficio del cómputo como recursos propios de la entidad bancaria: los bonos subordinados. A tal respecto, el inciso final del artículo 55 de la citada normativa dispone que "Regirá en lo demás lo dispuesto en la ley $N^{\circ} 18.045$, sobre Mercado de Valores", norma que en todo caso debe entenderse referida al Título XVI de la reseñada ley, que contiene los términos generales de las emisiones de bonos por parte de las sociedades chilenas.

d) Complementariedad: nuevamente se siguen en este punto los planteamientos tradicionales sobre la contabilización de las financiaciones subordinadas como recursos propios de "segundo orden" o complementarios. A diferencia del capital primario, la asimilación al patrimonio efectivo del banco se encuentra limitada: así, el artículo 66 de la Ley general de bancos dispone que su cómputo sólo llega hasta el equivalente al cincuenta por ciento del capital básico. Ello no implica que exista impedimento a que un banco emita bonos subordinados por montos superiores, sino sólo una limitación a la contabilización del exceso como patrimonio efectivo para los fines regulatorios pertinentes.

e) Publicidad: conforme a lo dispuesto en la sección III.2 del capítulo 2-11 de la Recopilación Actualizada de Normas de la SBIF, el hecho de la subordinación debe constar en la escritura de emisión de bonos. Puede señalarse este requisito como propio del carácter público que debe tener una subordinación de créditos, pero estimamos que ello responde, en este caso, a que el hecho de la subordinación requiere de una disposición expresa. No podría sostenerse que un título ha sido emitido con el carácter de subordinado sin una cláusula de subordinación que conste propiamente en la escritura de emisión, dado que es necesario excluir la regla de la distribución proporcional de los supuestos concursales. Donde sí encontramos una referencia expresa a la publicidad del carácter subordinado de las emisiones de esta clase de títulos es en la sección III.3.4 del señalado capítulo 2-11, en cuanto se dispone que

la Recopilación Actualizada de Normas de la SBIF dispone que: "Para determinar el plazo promedio, cuando los bonos contemplen amortizaciones parciales, se multiplicará el importe de cada cuota de amortización por su plazo, expresado en dias o meses, según corresponda. Luego se sumarán los productos obtenidos de esas operaciones y el resultado de la suma se dividirá por el importe total de la emisión. El cuociente [sic] que se obtenga indicará el plazo promedio del bono, expresado en días o meses, según cual haya sido el factor utilizado". 
la indicación del carácter subordinado de los bonos debe estar contenida en el prospecto de emisión disponible al público.

f) Ajenidad al sistema financiero: A pesar de sus similitudes, he aquí una diferencia sustancial con el sistema comunitario. El artículo 55 de la Ley general de bancos dispone que: "Los bonos subordinados no pueden ser adquiridos en forma alguna por bancos o demás instituciones sujetas a la fiscalización de esta Superintendencia, nipor sociedades fliales o coligadas de dichas instituciones." La ampliación de la restricción a toda otra entidad sujeta a la fiscalización de la SBIF se justifica en un mercado tan pequeño como el chileno, no bastando la prohibición sólo respecto a las entidades relacionadas al banco emisor.

Cabe agregar que, dado el carácter de Derecho común de la legislación civil, todo cuanto no se encuentre expresamente tratado en la legislación bancaria debe ser suplido mediante las disposiciones generales de la subordinación de créditos contenidas en el artículo 2489 CCCh., conforme a la nueva redacción incorporada por la Ley $\mathrm{N}^{\circ} 20.190$, de $2007^{58}$. En tal sentido, y a contar de la entrada en vigor de la citada ley, las emisiones de bonos subordinados por parte de los bancos están sujetas a ciertas reglas adicionales, de las cuales queremos destacar las siguientes:

Una primera cuestión se refiere en la posibilidad de que los acreedores subordinados, probablemente en concierto con el deudor, pudiesen revocar el carácter subordinado de los bonos. Esta cuestión redunda, en consecuencia, en determinar el grado de protección que deben recibir los acreedores beneficiarios. Éstos buscarán la permanencia de la subordinación, aun cuando no hayan formado parte del instrumento en que ésta conste. Atendido el hecho de que la principal finalidad de la financiación subordinada es su asimilación

${ }^{58} \mathrm{Al}$ incorporar toda una regulación general para los negocios de subordinación en el año 2007, bien puede señalarse la intención del legislador de dar reconocimiento a una práctica largamente utilizada en el contexto de los recursos propios de las entidades de crédito, en otros ámbitos en que tales negocios no habían sido expresamente reconocidos. De hecho, con anterioridad a la promulgación de la citada Ley No 20.190, ciertos autores ya habían objetado la posibilidad de que los particulares acordasen subordinaciones de crédito más allá del contexto bancario [véase: UGARTE GoDOY, José Joaquín, cit. (n. 56), pp. 373-389], basándose principalmente en la idea de la infracción al principio de legalidad de las preferencias (artículo $2.470 \mathrm{CCCh}$ ) y al orden público que envolvería todas las reglas de prelación de créditos,

Por ello, si hay un aspecto que cabe destacar respecto a la regulación propuesta por la reseñada ley es su deseo de amplitud. La definición de la subordinación -o, mejor dicho, del negocio que le da origen- se encuentra en el nuevo inciso $4^{\circ}$ del artículo 2.489 CCCh., que dispone que se trata de "un acto o contrato en virtud del cual uno o más acreedores de la quinta clase aceptan postergar, en forma total o parcial, el pago de sus acreencias en favor de otro u otros créditos de dicha clase, presentes o futuros", cubriendo la más amplia variedad de negocios que, por diversos motivos, tengan por finalidad que el crédito se sitúe en un orden inferior en la escala de prelación. 
a los fondos propios de la empresa, es sobre la confianza de su estabilidad que nuevos financiadores estarán dispuestos a otorgar mayor crédito al deudor. Si esa confianza no está lo suficientemente justificada, este modelo de financiación está condenado al fracaso.

Resolver este aspecto ha sido un punto de especial preocupación por la doctrina al enfrentar la naturaleza jurídica de la subordinación voluntaria de créditos, pero que ha sido finalmente resuelta por la nueva redacción del artículo 2489 CCCh., que en su parte pertinente dispone que: "La subordinación también podrá ser establecida unilateralmente por el deudor en sus emisiones de titulos de crédito. En este último caso, y cuando sea establecida unilateralmente por el acreedor que acepta subordinarse, será irrevocable".

Por su parte, el inciso final del artículo 2489 CCCh. Dispone: "La subordinación obligará a los cesionarios o herederos del acreedor subordinado y el tiempo durante el cual se encuentre vigente no se considerará para el cómputo de laprescripción de las acciones de cobro del crédito". La parte que nos interesa es la frase final, la cual dispone implícitamente un supuesto de "suspensión" de la prescripción extintiva de las acciones de cobro del crédito subordinado (artículo 2509 CCCh.). En este caso, ello implica que no se iniciará el cómputo del plazo de prescripción mientras la obligación beneficiaria no se haya extinguido o mientras no se haya puesto término a la subordinación voluntaria por cualquier otra causa.

Pero he aquí una confusión de conceptos en tanto la suspensión de la prescripción no tiene sentido en este ámbito. La cláusula de subordinación no afecta la exigibilidad del crédito, sino sólo la graduación del crédito a efectos de las reglas de prelación. Error que se hace patente en los supuestos de financiaciones subordinadas que, configuradas como casos de subordinación general (esto es, respecto a todos los demás acreedores valistas), de manera que los créditos beneficiarios son una masa determinable sólo al tiempo de efectuar los pagos en el ámbito del concurso. Así, lo normal es que el deudor (el banco) tenga, y vaya adquiriendo en el camino, una serie de créditos ordinarios que extenderían ad infinitum el plazo de prescripción de las acciones de los acreedores subordinados, lo que contraviene los principios de seguridad jurídica a los que pretende dar respuesta la prescripción extintiva.

\section{Régimen jurídico de los bonos subordinados en situaciones de crisis.}

Ahora bien, para efectos de una breve revisión del valor de las financiaciones subordinadas en el marco de las crisis de las entidades financieras, vale una breve explicación preliminar. El ordenamiento jurídico chileno, asumiendo la importancia del sector bancario en la economía general, ha establecido un régimen concursal especial para los bancos. Este sistema se caracteriza principalmente por el hecho de contar con ciertas herramientas anticipato- 
rias de la crisis, mecanismos preventivos de la insolvencia y procedimientos concursales propiamente tales. Revisaremos separadamente cada uno de ellos, principalmente desde la óptica de las consecuencias que tiene el hecho de que el banco haya procedido a la emisión de bonos subordinados.

a) Herramientas anticipatorias de la crisis. Las herramientas anticipatorias se refieren a los controles de solvencia efectuados por el órgano regulador. A este respecto, y respetando los postulados de "Basilea I", el artículo 66 de la Ley general de bancos contiene los dos índices principales de medición de la solvencia bancaria. Por una parte dispone que el patrimonio efectivo de un banco no podrá ser inferior al ocho por ciento de sus activos ponderados por riesgo, neto de provisiones exigidas ${ }^{59}$; y, por la otra, que el capital básico no podrá ser inferior al tres por ciento de los activos totales del banco, neto de provisiones exigidas. El concepto de "patrimonio efectivo" utilizado para el primero de tales índices está compuesto por las partidas señaladas en el mismo artículo 66, incluyendo: $i$ ) el capital pagado y reservas (capital básico); ii) los bonos subordinados, con las limitaciones antes apuntadas; y iii) las provisiones voluntarias que haya constituido, hasta concurrencia del uno coma veinticinco por ciento de sus activos ponderados por riesgo ${ }^{60}$. Finalmente, la misma norma agrega que, cuando un banco efectúe aportaciones a sociedades filiales o de apoyo al giro o asigne capital a una sucursal en el exterior, su "patrimonio efectivo" se calculará aplicando las normas generales de consolidación que establezca la SBIF ${ }^{61}$.

La Ley general de bancos hace un amplio uso de estas razones financieras, utilizándolas como parámetro permanente en el control de la actividad de la empresa, entre otros para: el condicionamiento a la autorización de la SBIF a la fusión de entidades bancarias (artículo 35 bis); el funcionamiento de la entidad mientras no se haya enterado completamente el capital mínimo

${ }^{59}$ Los criterios de ponderación por riesgo de los activos bancarios se encuentran contenidos en el artículo 67 de la Ley general de bancos.

${ }^{60}$ La sección 3.1 del capítulo 12-1 de la Recopilación Actualizada de Normas de la SBIF contiene un mayor detalle sobre las partidas que integran y se descuentan para la conformación del concepto de "patrimonio efectivo" de la entidad bancaria. En lo que nos interesa, no se agrega ninguna cuestión relevante en relación con los bonos subordinados.

${ }^{61}$ Para estos efectos, el capítulo 12-1 de la Recopilación Actualizada de Normas de la SBIF dispone que: "Las normas relativas al capital básico y patrimonio efectivo a que se refiere el articulo 66 de la Ley General de Bancos, se cumplirán considerando los activos consolidados del banco con: a) sus filiales en el pais, con excepción de las sociedades de apoyo al giro constituidas al amparo del articulo 74 de la Ley General de Bancos; $y, b$ ) sus sucursales of filiales establecidas en paises clasificados en primera categoría de riesgo, según lo indicado en el Capitulo 1-12 de esta Recopilación, por alguna de las empresas clasificadoras internacionales que alli se mencionan". 
(artículo 51); la clasificación de los bancos según sus niveles de solvencia (artículo 59); la presunción de hechos que dan cuenta de una afectación de la situación financiera del banco (artículo 118); y la presunción de hechos que dan cuenta que la entidad presenta problemas de solvencia (artículo 122).

b) Mecanismos preventivos. Como mecanismos preventivos, se establece la posibilidad de "capitalización preventiva" (artículos 118 y siguientes de la Ley general de bancos) y de "capitalización por medio del sistema financiero" (artículos 140 y siguientes del mismo cuerpo legal). Ninguno de ellos es estimado por la doctrina como procedimientos "concursales", por cuanto no implican la concurrencia de los acreedores de la institución bancaria a fin de satisfacer sus acreencias, sino de búsqueda de financiación sea por vía de aportes o mediante endeudamiento adicional para sortear ciertos problemas financieros ${ }^{62}$.

En el caso de la "capitalización preventiva", afectada que sea la situación financiera del banco -supuesto genérico que se presume en ciertos casos señalados por el mismo legislador-, el Directorio debe convocar a una Junta de Accionistas con el objeto de aprobar el correspondiente aumento de capital necesario para el normal funcionamiento de la entidad. Los bonos subordinados tienen importancia en esta cuestión por cuanto una de las presunciones indiciarias de que el banco se encuentra afectado en su situación financiera consiste en que su "patrimonio efectivo", descontadas las pérdidas acumuladas durante el ejercicio que aparezcan en un estado financiero, sea inferior al ocho por ciento de los activos netos de provisiones exigidas y ponderados por riesgo. Y, como hemos señalado, el artículo 66 de la Ley general de bancos admite para el cómputo de tal "patrimonio efectivo" la contabilización de los bonos subordinados, claro está, sujeto a las restricciones indicadas en la misma norma. Como resulta evidente, este índice está directamente vinculado a las herramientas de control anticipatorias de la solvencia de la empresa, que, en el inciso primero del citado artículo 66 exige que el "patrimonio efectivo" de los bancos siempre supere al ocho por ciento de sus activos ponderados por riesgo, neto de provisiones exigidas.

Por su parte, en el caso de la "capitalización por el sistema financiero", los fondos no son obtenidos por parte de los accionistas, sino mediante un préstamo a dos años por parte de otro banco. Ello tendrá lugar tanto para los casos en que se encuentre afectada la situación financiera del banco (mismo supuesto que para la otra forma de capitalización apuntada), como para los casos en que el banco revele problemas de solvencia que comprometan el oportuno pago de sus obligaciones (mismo supuesto que, como veremos,

${ }^{62}$ Por todos, Puga Vial, Juan Esteban, Derecho concursal. El juicio de quiebra (Santiago, Editorial Jurídica de Chile, 1999), p. 98. 
causa la presentación de convenios) o se encuentre sujeto a administración provisional. Lo interesante es que, conforme al artículo 140 de la Ley general de bancos, éste préstamo tiene el carácter de legalmente subordinado al resto de los acreedores valistas para el caso de concurso de acreedores. Ello significa el establecimiento de un supuesto de subordinación legal, general e incompleta por parte de la legislación chilena.

Nuevamente, la existencia de emisiones de bonos subordinados tiene importancia para este supuesto. Para la primera causal, esto es, que se encuentre afectada la situación financiera del banco, deben tenerse iguales consideraciones que aquellas señaladas en relación a la "capitalización preventiva”. Para el caso que el banco revele problemas de solvencia, el artículo 122 establece una serie de presunciones que acreditan la situación anterior, incluyendo que: " $e l$ patrimonio efectivo, después de deducidas las pérdidas acumuladas durante el ejercicio que aparezcan en un estado financiero, sea inferior a un cinco por ciento de los activos netos de provisiones exigidas y ponderados por riesgo."

Se sigue a este respecto igual técnica que para el caso de la "capitalización preventiva”, estableciendo una causal genérica (problemas de solvencia) y un conjunto de hechos reveladores de la misma, acudiendo al auxilio de los índices contemplados en la propia legislación bancaria como herramientas de control a la solvencia y estabilidad de las entidades bancarias. En ambos casos, debemos añadir, aparentemente se trata de un sistema de presunciones iuris tantum, en el sentido que los supuestos podrían ser desvirtuados mediante prueba en contrario por parte de la entidad bancaria. Ello significaría que ésta podría acreditar que pese a encontrarse en alguno de los supuestos contemplados por el ordenamiento como revelador de un problema financiero o de solvencia, tal situación no existe. Sin embargo, creemos que esta solución no es adecuada, dado que el sistema de "presunciones" se establece sobre la base de supuestos que infringen igualmente los índices requeridos por el ordenamiento: en este caso, particularmente la relación patrimonio efectivo / activos, requerida en el primer inciso del artículo 66 de la Ley general de bancos. De lo anterior se concluye la impropiedad del legislador al establecer un sistema de presunciones, cuando, en realidad, debería tratarse de medios de acreditación directa de la afectación a la situación financiera de la empresa o de problemas de solvencia, según el caso, sin perjuicio de poder contar con otras vías de prueba de tales causales genéricas para poner en movimiento las soluciones preconcursales y concursales previstas en el ordenamiento bancario.

De hecho, cabe tener presente que el artículo 68 de la Ley general de bancos dispone que: "el banco que no se encuentre ajustado a alguna de las proporciones que señala el artículo 66, deberá encuadrarse en ella dentro de un plazo de sesenta dias, sin perjuicio de incurrir en una multa del uno por 
mil sobre el déficit de patrimonio efectivo o capital básico, según corresponda, por cada día que lo mantenga." De igual modo, el artículo 56 de la misma ley agrega que: "Tampoco podrá repartirse dividendo con cargo a utilidades del ejercicio o a fondos de reserva, si por efecto de ese reparto el banco infringe alguna de las proporciones que fija el artículo 66." De lo anterior se deduce que el ordenamiento bancario no puede permanecer inmutable ante la evidencia del deterioro de los niveles de solvencia de las entidades bancarias.

c) Mecanismos propiamente concursales. Como mecanismos propiamente concursales, encontramos el "convenio preventivo" y la "liquidación forzosa”.

El convenio preventivo, análogo en su estructura al convenio preventivo general regulado actualmente en el libro IV del Código de Comercio, tiene lugar cuando la institución financiera presenta problemas de solvencia en el pago oportuno de sus obligaciones, de carácter transitorio y remontable. Al igual que en el caso de la capitalización por el sistema financiero, la emisión de bonos subordinados tiene importancia para la presunción de existencia de problemas de solvencia, en tanto participa de la conformación del "patrimonio efectivo" del banco. De hecho, el índice señalado en la correspondiente presunción se encuentra contenido en el artículo 122 de la Ley general de bancos, y es aplicable a la capitalización por el sistema financiero sólo por efectos de la remisión que efectúa el artículo 140 del mismo cuerpo legal.

No obstante, para el caso de los convenios preventivos, la existencia de bonos subordinados tiene una segunda importancia. Ya anticipábamos que el inciso final del artículo 55 de la Ley general de bancos dispone que: "Cuando el directorio del banco deba presentar convenio a sus acreedores y éste sea aprobado, los bonos subordinados que el banco adeude, estén o no vencidos, serán capitalizados por el solo ministerio de la ley hasta concurrencia de lo necesario para que la proporción entre el patrimonio efectivo y los activos ponderados por riesgo no sea inferior al doce por ciento. La transformación en acciones se efectuará en la forma que establece el articulo 127”. Revisemos brevemente esta cuestión:

Hemos señalado que una de las presunciones para probar los problemas de solvencia del banco se refiere al caso que el patrimonio efectivo, después de deducidas las pérdidas acumuladas durante el ejercicio que aparezcan en un estado financiero, sea inferior a un cinco por ciento de los activos netos de provisiones exigidas y ponderados por riesgo. También hemos dado cuenta que el concepto de "patrimonio efectivo" incluye a los bonos subordinados, sujeto a ciertas limitaciones (artículo 66 de la Ley general de bancos).

Si conforme a los términos del citado artículo 66, el "patrimonio efectivo" está compuesto también (y principalmente) por el capital básico de la entidad -esto es, el capital pagado y reservas-, cabe preguntarse de qué manera 
afecta el índice de solvencia el hecho de modificar la naturaleza de los bonos subordinados a capital. El orden de los factores no puede alterar el producto, de lo que se deduciría la inutilidad de la solución. Por ello, esta norma sólo tiene sentido en cuanto dejen de aplicarse las limitaciones contenidas en el artículo 66 de la Ley general de bancos para el cómputo de los bonos subordinados como parte de tal "patrimonio efectivo". Quiere decir lo anterior que, capitalizados que sean los créditos que emanan de la emisión de bonos subordinados, todo el monto adeudado pasa a formar parte del capital básico de la empresa, sin tomar en cuenta la limitación del cincuenta por ciento del capital básico ni de la reducción del valor en veinte por ciento por cada año que transcurra desde que falten seis años hasta su vencimiento.

Como segundo mecanismo concursal, la liquidación forzosa aparece como el procedimiento a seguir en caso que la insolvencia del banco, evidenciada por sus estados financieros, sea de tal gravedad que amerite incluso la cancelación de su autorización de existencia, procediéndose a la consecuente liquidación del activo ${ }^{63}$. Como indica Puga: "la causa del convenio es la insolvencia de la empresa financiera, pero esta insolvencia debe revestir características tales que permita, aunque sea mediante la inyección de capitales ajenos, revertir la crisis en un plazo prudente... En cambio, la liquidación forzosa entra en el juego cuando la situación es definitivamente desesperada, cuando no se justifica mantener viva la empresa.. [...]"64 Queda por revelar a qué clase de concurso se refiere el artículo 55 de la Ley general de bancos, al disponer que el efecto de la cláusula de subordinación sólo se producirá en caso de "concurso de acreedores". Aunque pudiese parecer que se trata de una referencia genérica a cualquiera de los dos mecanismos propiamente concursales contemplados en la misma ley (esto es, "convenio preventivo" y "liquidación forzosa"), estamos por la negativa, instando porque dicho concepto se refiere únicamente al procedimiento de liquidación forzosa. Lo anterior, por los siguientes motivos: primero, porque, como ya explicáramos, el inciso tercero del citado artículo 55 dispone la capitalización de la deuda para el caso de aprobación del convenio, y capitalizada que

${ }^{63}$ DE VeCCHIS, Pietro, cit. (n. 2), p. 90, agrega que: "La liquidación forzosa, al igual que la quiebra, constituye una fase patológica en el ciclo operativo de un banco, pero responde también a las exigencias fisiológicas del sistema, en cuanto instrumento de recambio de los operadores económicos y de expulsión del mercado a aquellos operadores que no tienen ya título o razón para permanecer en él”. Quiere decir lo anterior que, por mucho que el ordenamiento razone sobre la idea de la importancia del sistema bancario en la economía en general, pretendiendo el establecimiento de un cúmulo de soluciones preventivas y de salvamento, debe apreciarse siempre la necesidad de llegar a la solución última de la liquidación patrimonial.

${ }^{64}$ Puga Vial, Juan Esteban, cit. (n. 62), p. 109. 
ésta sea, difícilmente puede aplicársele una regla de prelación como la que supone la subordinación; y, luego, porque este es el sentido que le asigna el capítulo 9-6 de su Recopilación Actualizada de Normas de la SBIF. Así, al explicar el contenido del artículo 55 de la Ley general de bancos, dicha normativa dispone que: "En caso de que la entidad emisora se encuentre en concurso de acreedores, esto es, en estado de liquidación forzosa, estos bonos se pagarán después de los demás acreedores, incluidos los valistas, lo que les confiere su carácter de subordinados".

Por ello, la posposición de los créditos que emanan de la emisión de bonos subordinados sólo tendrá lugar en el caso de liquidación forzosa. Dada la importancia de las empresas bancarias en la economía nacional, se trata ésta de una solución absolutamente residual y excepcional. Residual dado que supone que las herramientas de control y los mecanismos preventivos no fueron suficientes como para evitar la crisis bancaria, que se ha rechazado la propuesta de convenio preventivo presentado por el Directorio del banco, o, genéricamente, que el Superintendente de la SBIF haya considerado que: " $e l$ banco no tiene la solvencia necesaria para continuar operando, o que la seguridad de sus depositantes u otros acreedores exige su liquidación". Y añadimos su carácter excepcional, en cuanto existen una serie de barreras para lograr que se lleve a efecto la liquidación forzada, dadas las nocivas consecuencias que ella implica, especialmente por el hecho de requerir una resolución fundada por parte de la SBIF y de la aprobación del Banco Central (artículo 130 de la Ley general de bancos).

\section{CONCLUSIÓN}

En cualquier situación de crisis financiera, la estabilidad del sistema bancario se encontrará en el ojo del huracán. Los variados juicios críticos que se darán a este respecto probablemente incidirán en la promulgación de normas más estrictas que aseguren la solvencia y solidez de las entidades de crédito. Sin embargo, dado que la obtención de recursos sólo a modo de capital puede verse ampliamente superada, el regulador debe echar buena mano a la imaginación para proveer de otros instrumentos (de deuda) que puedan asimilarse a los recursos propios de las instituciones financieras. Hace un buen tiempo que se ha encontrado en las financiaciones subordinadas, sujetas a ciertos límites de estabilidad y computabilidad, instrumentos idóneos para este fin, lo cual ha dejado profundas huellas en la normativa propuesta por el Comité de Basilea e, incluso, en las normativas comunitarias europeas. La mayor diversidad de riesgos a los que hoy en día se enfrentan los bancos ha dado pie a la continua búsqueda de un mejoramiento en las directrices que tratan de sus recursos propios y ha propiciado una mejor 
caracterización de las financiaciones subordinadas para una multiplicidad de fines regulatorios.

El modelo chileno, sin embargo, se ha quedado con los parámetros originalmente propuestos en "Basilea I", valorando únicamente los riesgos de mercado y desestimando, hasta el momento, las demás contingencias a las que se enfrentan las instituciones financieras, al menos desde la perspectiva del fortalecimiento de los recursos propios. La "hoja de ruta" para la adaptación de los acuerdos de "Basilea II" debe tomar en cuenta estas circunstancias, de modo de avanzar en el aseguramiento de la estabilidad del sistema. Para ello, no creemos necesario variar la tipología de las financiaciones subordinadas (aunque quizás sería positivo abogar por una neutralidad instrumental que permitiese la existencia de obligaciones subordinadas que no estuvieren materializadas únicamente en bonos), sino principalmente crear una diversidad mayor de ratios de control de los recursos propios al enfrentarse a las diferentes fuentes de riesgo. En este sentido, los modelos de "Basilea II" e, incluso, de las directivas comunitarias de 2006, han avanzado bastante en la materia.

[Recibido el 8 marzo y aprobado el 20 de octubre de 2010].

\section{BiBLIOGRAFÍA}

Borroni, Mariarosa, Prestiti subordinati e "debt capital" nelle banche italiane (Roma, Bancaria, 2006).

CAESAR, Camille, Capital-Based Regulations and U.S. Banking Reform, en Yale Law Journal, 101 (1992) 7.

Cesarini, Francesco, Aspettifunzionali e di mercato degli strumenti di ricapitalizzazione delle banche, en Portale, Giuseppe (director), Ricapitalizzazione delle banche e nuovi strumenti di ricorso al mercato (Milano, Giuffré, 1983).

DE VeCCHIs, Pietro, Aspectos jurídicos de las crisis bancarias en Italia, en VV. AA., Aspectos jurídicos de las crisis bancarias (Respuesta del ordenamiento jurídico) (Madrid, Gráficas Lorno, 1998).

FERnÁndez Del Pozo, Luis, El fortalecimiento de recursos propios (Madrid, Marcial Pons, 1992).

Fernández del Pozo, Luis, Las participaciones preferentes (Cizur Menor, Thomson Civitas, 2005).

FERNÁNDEZ RodrígueZ, Tomás Ramón, Aspectos administrativos de las crisis bancarias, en VV. AA., Aspectos jurídicos de las crisis bancarias (Respuesta del ordenamiento jurídico) (Madrid, Gráficas Lorno, 1998).

Lown, Cara - Peristani, Stavros - Robinson Kenneth J., Capital Regulation and Depository institutions, en Barth, James - Brumbaugh, Dan Jr. y - Yago, Glenn (editores), Restructuring Regulation and Financial Institutions (Estados Unidos de América, Klower Academic Publishers, 2001). 
McCormick, Roger - Creamer, Harriet, Hybrid Corporate Securities (Londres, Sweet \& Maxwell, 1987).

Onado, Marco, Aspetti economici e tecnici, en Portale, Giuseppe (director), Ricapitalizzazione delle banche e nuovi strumenti di ricorso al mercato (Milano, Giuffré, 1983).

PORTALe, Giuseppe, La recapitalizzazione delle aziende di credito (probleme e ipotesi), en Portale, Giuseppe (director), Ricapitalizzazione delle banche e nuovi strumenti di ricorso al mercato (Milano, Giuffré, 1983).

Portale, Giuseppe, Prestiti subordinati e prestiti irredimibili (apunti), en Banca Borsa e Titoli di Credito, 46 (1996) 1.

Poveda, Raimundo, La reforma de los coeficientes de solvencia, en Papeles de Economía Española, 44 (1990).

Puga Vial, Juan Esteban, Derecho concursal. El juicio de quiebra (Santiago, Editorial Jurídica de Chile, 1999).

Rojo Fernández-Río, Ángel, Crisis de la empresa y procedimientos concursales, en Anales de la Academia Matrisense del Notariadok, 23 (1982).

SAPPIDDEM, Razeen, The Regulation of Credit, Market and Operational Risk Management Under the Basel Accord, en Journal of Business Law, 1 (2004).

SCHNEIDER, Uwe, Finanziamenti subordinati come capitale proprio a fine di vigilanza negli Stati Uniti, en PorTale, Giuseppe (director), Ricapitalizzazione delle banche e nuovi strumenti di ricorso al mercato (Milano, Giuffré, 1983).

Talmor, Eli, A Normative Approach to Bank Capital Adequacy, en The Journal of Financial and Quantitative Analysis, 15 (1980) 4.

TApia Hermida, Alberto Javier, La financiación externa de las cajas de ahorro, en particular las obligaciones subordinadas y las cuotas participativas, en Revista de Derecho Bancario y Bursátil, 43 (1991).

Ugarte Godoy, José Joaquín, Sobre la posibilidad de pactar que una obligación tenga el carácter de subordinada en el Derecho chileno, en VARAs BRAUn, Juan Andrés - Turner Saelzer, Susan (coordinadores), Estudios de Derecho Civil: Código y Dogmática en el Sesquicentenario de la Promulgación del Código Civil. Jornadas Nacionales de Derecho Civil, Valdivia (Santiago, LexisNexis, 2005).

Uyemura, Dennis - van Deventer, Donald, Financial Risk Management in Banking (Estados Unidos de América, Bankline, 1993).

Wu, Eric, Basel II: A Revised Framework, en Annual Review of Banking and Financial Law, 24 (2005).

Zancada Peinado, Fermín, Los ratios de medición de solvencia, consideración especial de las entidades de depósito y la reciente reforma en España, en Papeles de Economía Española: Suplementos sobre el Sistema Financiero, 13 (1986). 